\title{
SOME SPECIES OF EULECANIUM (COCCIDAE) FROM FRANCE.
}

BY T. D. A. COCKERELL, EAST LAS VEGAS, N. MEX.

Dr. P. Marchal has sent me five species of Eulecanium collected in France. It might be supposed that these insects, coming from such a country, would be easily referred to well-known species; but as a matter of fact their identification has given me much trouble. Judging them by the standards of specific distinction laid down by Signoret, they could all be regarded as new to science. However, it is now generally admitted that Signoret over-divided his species, and an extreme view in the opposite direction is held by Mr. R. Newstead, who writes me that in his opinion Lecanium capreae, genevense, and fuscum (at least as understood in England) are one species; and further, that $L$. persicae, rosarum, and sarothamni are also one. This surprising union of species hitherto regarded as distinct must be taken seriously, for Mr. Newstead has gone over the ground very carefully, and would not make such a statement without excellent reasons. It was otherwise when Förster proposed to unite the whole series of Eulecanium under the specific name vagabundum.

The measurements of antennae and legs in this paper are all in micromillimeters. The paper is based wholly on females. The tarsus is always measured without the claw.

Eulecanium magnoliarum Ckll. var. hortensiae, var. noz.

On Hortensia (i.e. Hydrangea); Nice, July, r899. (Marchal No. 7.)

Rather light ferruginous, elongated, with a strong and sharp dorsal keel (in dried examples); surface rugose and tuberculate. The scales appear to have been variegated with black and yellow when alive.

Scales crowded, overlapping; long. $5^{\frac{1}{3}}$, lat. 3 , alt. about $\mathrm{I} \frac{1}{2} \mathrm{~mm}$.

Legs: femur and trochanter, I80; tibia, 120; tarsus, 93. Legs not as described for L. berberidis. 1

Antennae 8-jointed, 3 and 4 very variable; three antennae measured thus :

Joints :

$\begin{array}{cc}\text { (I.) } & (2 .) \\ 45 \cdot & 52 \\ ? & 45 \\ ? & 42\end{array}$

(2.)

(3.)

(4.)

(5.)

(6.)

(7.)

$52 . \quad 4.5$.

75 .

45.

33 .

60.

66.

42.

42. 65 .

57 .

48.

27.

27.

30.

42.

35 .

45 .

1 Externally, the Lecanium berberidis of Berlese and Leonardi (Cherm. Ital.) is very like $E$. hortensiae, having the same shape, same keel, and pustulated surface. It differs from $E$. hortensiae in being larger, much redder, and without the black or blackish marbling. I doubt its identity with the true $L$. berberidis. 
The typical $E$. magnoliarum was found in California under circumstances indicating that it was imported from Japan. No doubt $E$. hortensiae reached France from the Orient, and it is not native anywhere in Europe. Of the native French species, the nearest to it is Eulecanium genistae (Signoret).

These forms are placed in Eulecanium, but they show a good deal of resemblance to Calymnatus.

\section{Eulecanium Ciliatum Douglas, var. $\boldsymbol{\alpha}$.}

Marchal No. r2. Collected in France in 1900 (exact locality not stated).

Rather large, moderately convex, dark ferruginous, with a prominent but very broad and blunt longitudinal keel; sides deeply and coarsely pitted.

Two scales measure thus:- long. $6 \frac{1}{2}$, lat. 5 , alt. $3 \mathrm{~mm}$. long. 5, lat. 4 , alt. $2 \frac{2}{3} \mathrm{~mm}$.

Anterior leg: femur + trochanter, 162 ; tibia, II 4 ; tarsus, 78 .

Antennae 6-jointed; joints : (I.) $36,(2) 30,.(3) 98,.(4)$.2 , (5.) $18,(6) 36$.

This species is new to France; it was sent as doubtful $E$. robiniarum, which it evidently is not. In the structure of the scale, with the prominent long smooth dorsal area, limited on either side by pits, $E$. ciliatum exactly resembles the American $E$. canadense and kansasense, which are well figured by Hunter in Kansas univ. quarterly, April, 1899, Pl. xiv.

The antennae of the present insect (but not the scale) agree with $E$. websteri, kingii, and armeniacum, and nearly with tarsale. The antennae also resemble quite closely those of $E$. rosae (but joint 2 is too short), prunastri, and kansasense (but joint 3 is too long).

EUleCANIUM GENEvenSe var. MARChali, var. nov.

On Rosa ; Fontenay (Seine); Marchal No. 3 .

Light ferruginous; easily known from $E$. rufulum by its somewhat larger size, more shining surface, and deeply pitted sides. There is no distinct longitudinal keel. Long. $4 \frac{1}{2}$, lat. $3 \frac{2}{3}$, alt. $3 \mathrm{~mm}$. After boiling in liquor potassae the skin becomes nearly clear, but the area around the anal lobes remains brown. The antennae are 7 - to 8 -jointed (one specimen has the left antenna with 7 , and the right with 8 joints), short and rather stout, without the long bristles of $E$. rubi. The tessellation of the skin is very distinct in places.

Anterior leg: femur + trochanter, 150 ; tibia, 90 ; tarsus, 78 .

Measurements of three antennae:

\begin{tabular}{|c|c|c|c|c|c|c|c|c|}
\hline Joints : & (I.) & (2.) & (3.) & (4.) & (5.) & (6.) & (7.) & (8.) \\
\hline & I 5 (prox.) & 21. & 72. & 27. & 25 . & I8. & 23. & - \\
\hline & $?$ & 27. & 84. & 27. & 27. & 21. & 28. & - \\
\hline & ? & 24 . & 42. & 36. & 33. & 3о. & 24. & \\
\hline
\end{tabular}


This is near to $E$. genevense, and is provisionally regarded as a variety of it, but genevense, and also the forms said by Mr. Newstead to be identical with it, are always described as having 6-jointed antennae.

The 7 -jointed antenna is of the general type of $E$. maclurarum, but the third joint is much too short. The 8-jointed antenna is not unlike the E. rosarum of King and Reh, which I feel persuaded is not the true E. rosarum. The 7 -jointed antenna is not at all like the 7 -jointed form of the King and Reh E. rosarum.

\section{EuleCANIUM ALNI var. RUFUlum, var. nov.}

Dr. Marchal sent two lots, one on Carpinus, La Vienne, France, July 25 , I 896 ; the other marked "Lecanium quercus, Department de la Vienne, France," June $6, \mathbf{1} 896$.

Rather small, light ferruginous, convex, not shiny; not keeled, nor punctured. Long. $3 \frac{1}{2}-4$, lat. $2 \frac{4}{5}-3$, alt. $1 \frac{3}{4}-2 \mathrm{~mm}$.

Legs: femur + trochanter, I26--135; tibia, 84-96; tarsus, 60-69. The legs and antennae are very slender; width of femur, 30-33; width of tibia, I2-15.

Antennae 7 -jointed, varying to 6 and 8 . Measurements of four antennae :

$\begin{array}{lcccccccc}\text { Joints : } & (\mathrm{I} .) & (2 .) & (3 .) & (4 .) & (5 .) & (6 .) & (7 .) & (8 .) \\ & ? & 30 . & 75 . & 2 \mathrm{I} . & 2 \mathrm{I} . & 54 \cdot & - & - \\ & \text { 30. } & 33 . & 90 . & 24 . & 2 \mathrm{I} . & 78 . & - & - \\ & ? & 30 . & 93 . & 18 . & 24 . & 18 . & 30 . & - \\ & ? & 27 . & 75 . & 2 \mathrm{I} . & 18 . & 18 . & 15 . & 24 .\end{array}$

It will be observed that the third joint always remains very long, even in the 8-jointed forms. The 8-jointed antennae are near those of $E$. rugosum, but the scale is different.

I have not seen the typical E. alni Modeer (Lecanium alni Douglas, Ent. mo. mag., Sept. I886, p. 80-8 I), nor did Signoret recognize it. Douglas found it at Lewisham and Catford, England, on alder. The proposal to treat E. rufulum as a variety of $E$. aln $i$ is provisional, and depends upon a strong similarity which seems to be indicated by Modeer's original (1778) description.

\section{EULECANIUM PRUNASTRI Fonsc., var. a.}

Marchal No. I 4, on peach, at Cette, June, r 898.

Small and very dark, almost black, very convex, no longitudinal keel, sides more or less malleate. Three examples measure :

Long. $3 \frac{1}{3}$, lat. $3 \frac{1}{4}$, alt. $2 \$ \mathrm{~mm}$.

$\begin{array}{lllllll}\text { “ } & 3 \frac{1}{3}, & \text { “ } & 3 \frac{1}{2}, & \text { “ } & 2 \frac{1}{2} & \text { “ } \\ \text { “ } & 2 \frac{1}{2}, & \text { " } & 3 & \text { “ } & 1 \frac{3}{4} & \text { " }\end{array}$


The scale is unusually dark and strongly chitinized. There is a punctured band running anteriorly from the anal plates in the middle line.

Antennae 8-jointed. Below I give measurements of the antennae of the present insect, and also of 6- and 7-jointed E. prunastri, from slides prepared by Mr. Pergande.

$\begin{array}{lcccccccc}\text { Joints : } & (\mathrm{I} .) & (2 .) & (3 .) & (4 .) & (5 .) & (6 .) & (7 .) & (8 .) \\ & ? & 33 . & 42 . & 24 . & 36 . & 21 . & 18 . & 33 . \\ & ? & 45 . & 45 . & 60 . & 17 . & 21 . & 34 . & - \\ & ? & 30 . & 90 . & \text { I7. } & 21 . & 34 . & - & -\end{array}$

\section{BUTTON-BUSH INSECTS.}

BY JAMES G. NEEDHAM, LAKE FOREST, ILL.

Entomologists who collect from flowers know how many insects gather about the heads of the button-bush - the "honeyballs" of popular nomenclature. These heads are conspicuously white, their fragrance is very marked, their nectar is abundant, often filling the corollas so full that short-tongued insects may sip from them, and the protandrous stamens heap their pollen upon the style knob, which then protrudes conveniently for the benefit of pollen feeders. By carefully watching these flowers through their season, one may obtain nearly all the flower-visiting insects of his neighborhood.

My own too brief season of butterfly collecting was spent at Piasa Bluffs on the Mississippi, where there were a few button-bush clumps along the river banks under the edge of the bluffs; and there the butterflies swarmed - all the butterflies of that vicinity. They made a picture there which I shall always remember with delight. Dozens of them in a bright hued throng, poising on the swaying heads, or hovering over the dark green clumps that were set at the outer edge of a thin fringe of vegetation that stretched between the gray cliffs above the shining river below.

The predominant visitors are butterflies, but this predominance is unduly apparent because these are so conspicuous. Robertson (Bot. gaz., vol. 16, 65-66) lists 60 species of insects as visitors to the button-bush flowers. Of these 26 are butterflies and 20 are bees.

I spent the summer of 1899 in Lake Forest ; and there, under favorable conditions, began a study of the insects affecting the button-bush - not the transient visitors of the flowering season, but the resident insects that enter more closely into ecological relations with it. I found some 30 species of these, and made some observations on the habits of many of them. I planned to continue my observa- 

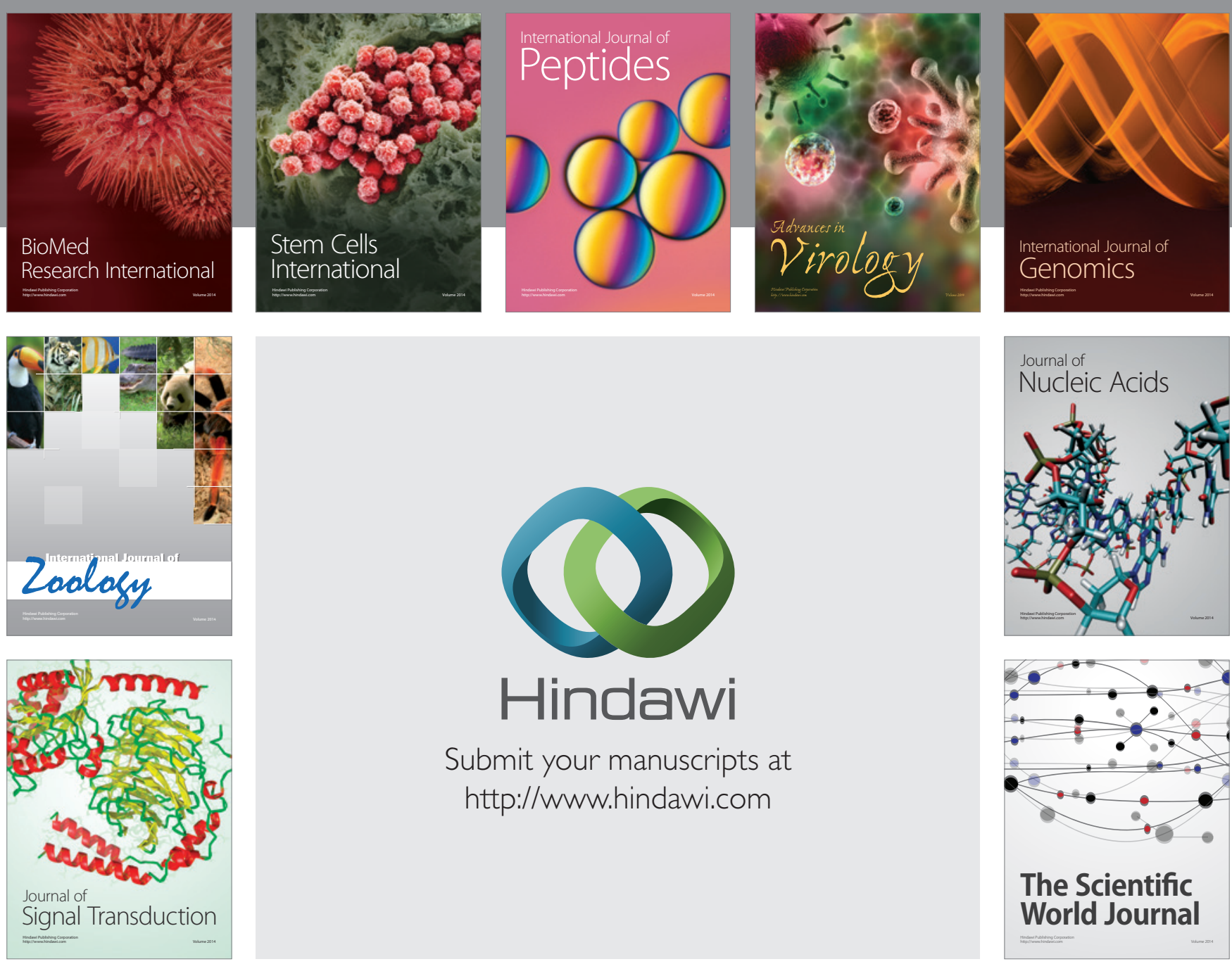

Submit your manuscripts at

http://www.hindawi.com
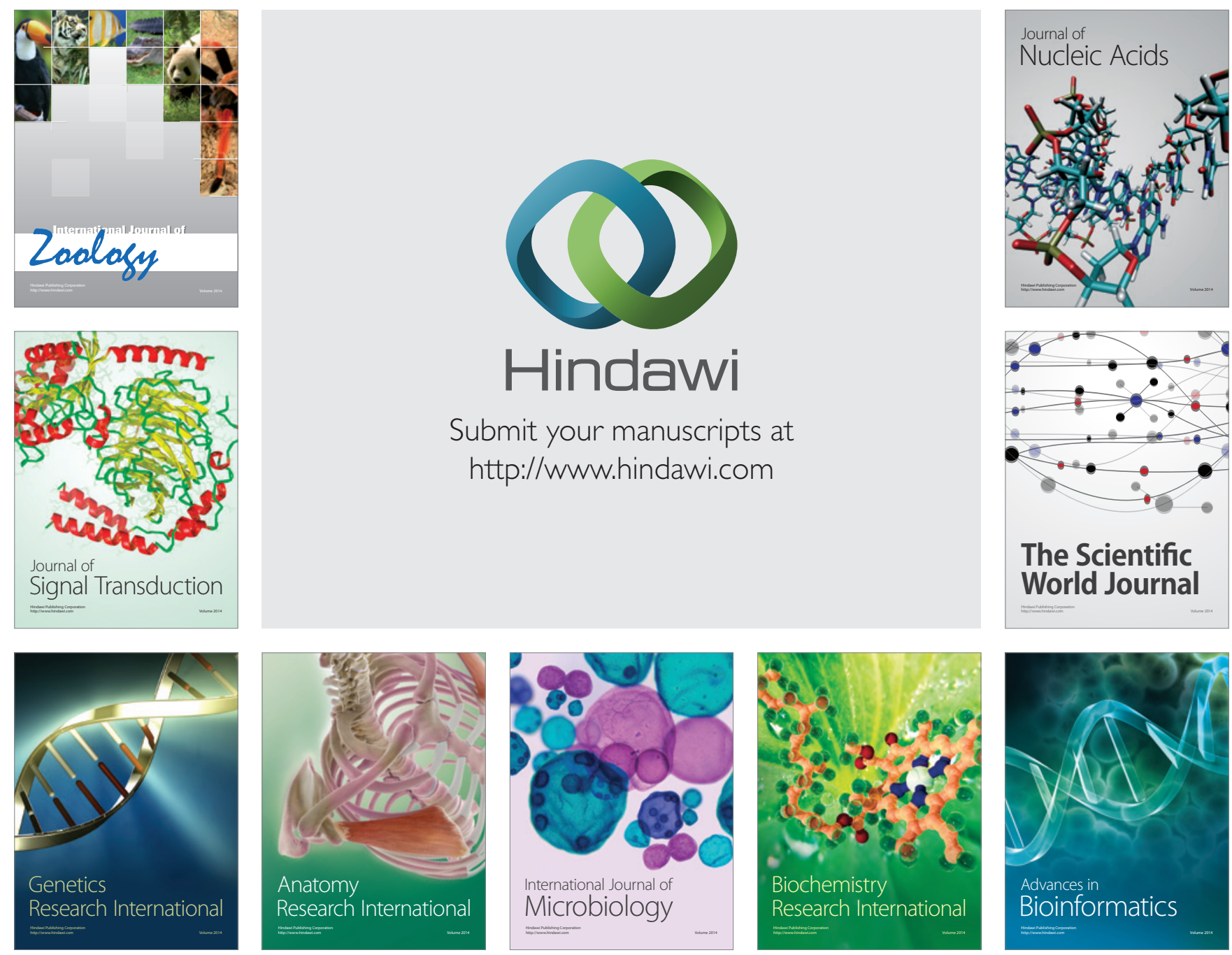

The Scientific World Journal
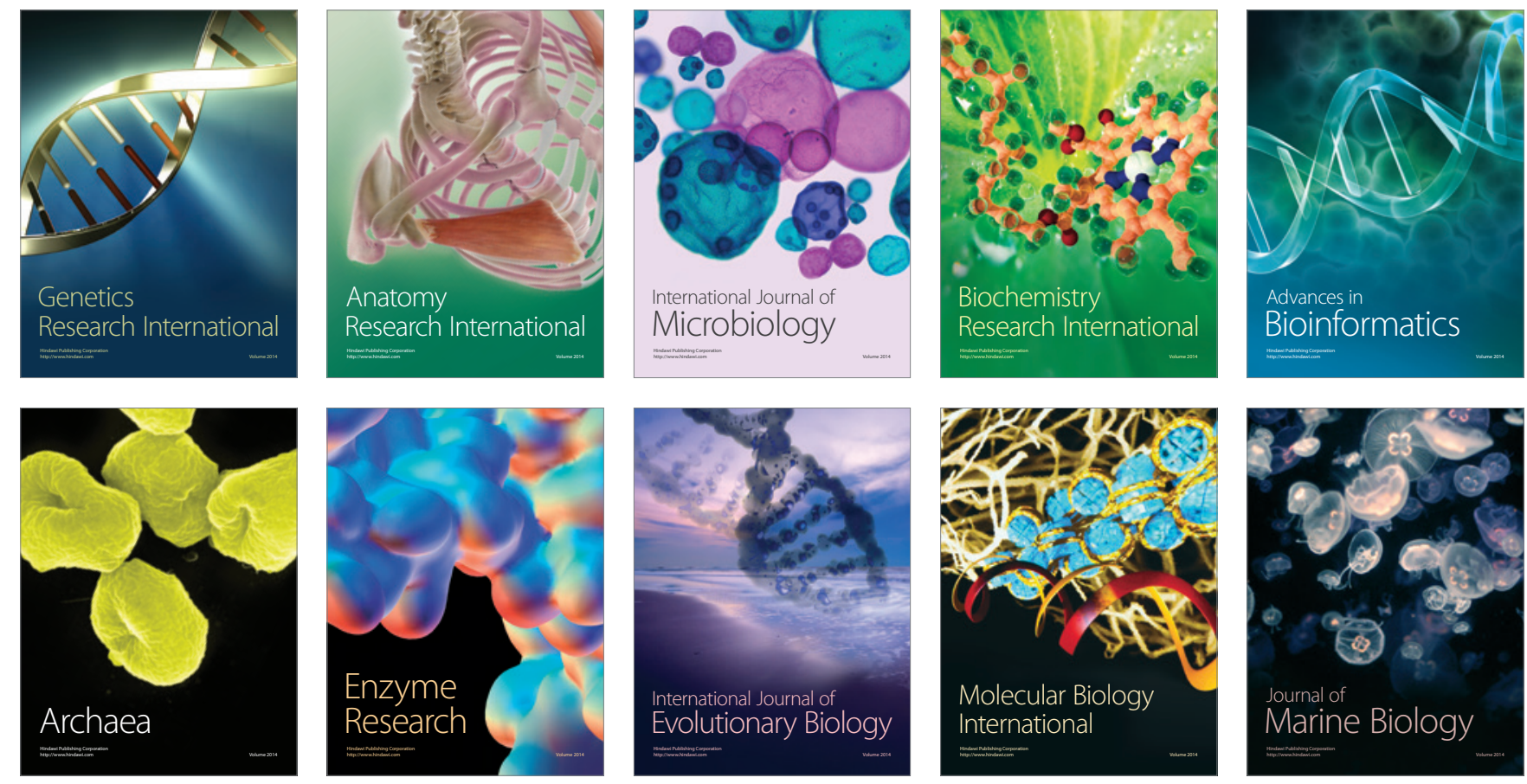